Butwal Campus Journal, Vol. 3, No. 1: 113-124, July 2020

Research Management Cell, Butwal Multiple Campus, Tribhuvan University, Nepal

\title{
EVALUATION OF PHYSICO-CHEMICAL PARAMETERS OF POUCH MILK SAMPLES AVAILABLE IN BUTWAL
}

\author{
Deepak Kumar Shrestha* \\ *Assistant Professor, Butwal Multiple Campus, Butwal, TU
}

Article History: Received 15 May 2020; Reviewed 30 May 2020; Revised 30 June 2020; Accepted 12 July 2020

\begin{abstract}
In the present study four different brands of pouch milk samples viz, DDC, Lumbini, Godhuli and Panchamrit commercially available in Butwal city were collected and the physicochemical characteristics including- moisture, $\mathrm{pH}$, casein and fat were analyzed. It was found that all measured parameters were found as per recommended standard as compared with reported nutritional quality of milk from various countries. The main objective of the study is to determine some of the physico-chemical properties of milk sample and to provide nutritional benefits for health. All these tests were carried out in Chemistry laboratories of BMC and DDC in Butwa Industrial Area. The value of $\mathrm{pH}$ ranged from 6.69 to 6.72 , moisture ranged from $90.5 \%$ to $91.45 \%$, the casein ranged from 3.12 to 3.4 and fat ranged from $2.87 \%$ to $3.06 \%$, where Lumbini pouch milk had highest $\mathrm{pH}$ while Godhuli had highest moisture content and casein also while Lumbini had highest fat content. These parameters were determined and data were analyzed from period of 15 March 2019 to 30 May 2019.
\end{abstract}

Keywords: physicochemical characteristics - pouch milk, -milk analysis

\section{INTRODUCTION}

Milk is an important sources of all basic nutrients required for mammals including human beings. Milk is a complex colloidal solution (emulsion) containing fat globules, casein micelle and whey proteins in aqueous solution of lactose, minerals and few other minor 
compounds. Milk is nearly complete food and contains all the essential components in nearly balanced form. Milk is the characteristics secretion of mammary glands of all mammals. In 2011, FAO estimates $85 \%$ of all milk worldwide is produced from cow, about $11 \%$ by buffaloes, $2 \%$ by goats, $1.4 \%$ by sheep and $0.2 \%$ by camels. So cow's milk dominates commercial production worldwide.

Fresh milk contains all the essential nutrients as lactose, fat, protein, minerals and vitamins in balanced ratio rather than other food (Hossain et al., 2013). According to (Byron et al., 1974) the average composition of fresh milk is water $87.20 \%$, dry matter $12.80 \%$ (fat $3.70 \%$, Protein $3.50 \%$, Lactose $4.90 \%$ and Ash $0.70 \%$ ). The average composition of the milk of each of several mammals is given by Imran Mohammad (I. Mohammad et al., 2008) pH in the range of $6.59-6.93$, moisture in the range of $76.4 \%$ to $86.8 \%$ and casein in the range of $2.18 \%$ to $3.26 \%$ among buffalo, cow and goat. According to R. Minard (Penn State Univ. Department of Chemistry, USA) (R.Minard et al., 1990) moisture in range of $90.6 \%$ to $87.4 \%$, casein in the range of $2.0 \%$ to $5.5 \%$, fat in range of $1.1 \%$ to $6.5 \%$ and lactose in the range of $4.5 \%$ to $7 \%$ among horse, cow, human, goat and sheep.

Milk from various mammals such as human, cow, buffalo, goat, sheep, camel etc. are used for different nutritional purposes such as feeding to young ones and preparation of some nutritional products such as milk cream, butter, yogurt, ghee, cheese, ice milk, sour milk, hot chocolate, pudding etc. (Webb et.al., 1974 Hassan, 2005). Consumers always demand nutritionally enriched milk and dairy products (Kamao et al., 2007). Early lactation milk contains colostrums, which carries the mother's antibodies to its young and can reduce the risk of many diseases. Interspecies consumption of milk is not uncommon, particularly among humans, many of whom consume the milk of others mammals. (Bhatia et al., 2015).

As an agricultural product, milk is extracted from non-human mammals during or soon after pregnancy. India is the world's largest producer of milk, and is the leading exporter of skimmed milk powder, yet it exports few other milk products. The ever increasing rise in domestics demand for dairy products and a large demand supply gap could lead to India being a net importer of dairy products in the future. The United State, India, China and Brazil are the world's largest exporters of milk and milk products. Throughout the world, more than six billion people consume milk and milk products. Over 750 million people live in dairy farming households. (Bhatia et al., 2015). 
Mammals consume milk in the nutritionally significant weeks following birth. Whole milk contains vitamins (principally thiamin, riboflavin, pantothenic acid and vitamins A, D, and $\mathrm{K}$ ), minerals (calcium, potassium, sodium, phosphorus, and trace metals), proteins (which includes all the essential amino acids), carbohydrates (chiefly lactose) and lipids (fat). The only important elements in which milk is seriously deficient are iron and vitamin C. Infants are usually born with storage supply of iron large enough to meet their needs for several weeks. Vitamin C is easily secured through an orange juice supplement.

Pasteurization is important processing of milk for two purposes-one for public health aspect and another for keeping quality aspect. Pasteurization is used to kill harmful pathogenic bacteria by heating the milk for a short time and then immediately cooling it. Types of pasteurized milk include full cream, reduced fat, skim milk, calcium enriched, flavored, and UHT (Ultra Heat Treatment). The standard high temperature short time (HTST) process of 720 C for 15 seconds completely kills pathogenic bacteria in milk, (Ball et al., 1943) rendering it safe to drink for up to three weeks if continually refrigerated (Ranieri et al., 2009). Dairies print best before dates on each container, after which stores remove any unsold milk from them shelves. A side effect of the heating of pasteurization is that some vitamins and mineral contents are lost. The main objectives of this study are to determine some of the physicochemical characteristics of different pouch milk, to give baseline information regarding for human consumption and to find out the benefits of milk for human health. The significances of the study are: to find out the addition of water or other components which carry poor quality of milk, to improve farming and marketing technology for milk and to take step against selling of poor quality of milk.

\section{RESEARCH METHODS}

\section{The sample}

The present experiment were conducted in Chemistry lab of BMC and laboratory of DDC in Butwal Industrial Area. To perform the experiment, four commercial brand of pouch milk samples Viz, DDC, Lumbini, Godhuli and Panchamrit were selected from different sites of local market of Butwal. They were kept in refrigerator until analysis. 


\section{Samples preparation}

Collected samples were divided into four portions. The first portion was used for the isolation of lactose content in samples. The second portion was used to determine moisture content in milk. The third portion was used to determine the fat content in milk. The last portion was used to determine the $\mathrm{pH}$.

\section{Physical analysis}

The physical parameters were determined shortly after they were brought to the laboratory according to AOAC 2000's method. The $\mathrm{pH}$ was determined by $\mathrm{pH}$ meter (HI 98107, HANNA Instruments, Romania). Moisture content was determined gravimetrically by the difference between known weight of milk sample and the determined wt. of total solid after evaporating the liquid component of the milk sample on a hot plate.

\section{Chemical analysis}

Different chemical parameters such as total fat content was determined by modified Gerber Method (Acid-Butyrometer) while casein was determined by Gravimetric Method (Khadka N.M et al., 2013).

\section{Statistical analysis}

The primary data was collected after the experimentation and observation in the lab. The statistical analysis was done as per Steel and Torrie (1980), using Completely Randomized Design (CRD). The data was analyzed using appropriate statistical tools such as bar diagram, line graph etc. to find out the statistical differences within the quality of four different types of pouch milk samples.

Table 1: Methods used for data analysis

\begin{tabular}{cc}
\hline Parameters & Methods employed \\
\hline $\mathrm{pH}$ & $\mathrm{pH}$ meter \\
Moisture content & Change in initial and final weight \\
Casein & Gravimetric Method \\
Fat & Modified Gerber method \\
\hline
\end{tabular}

\section{Required chemicals and reagents}

Acetic acid, Acetone, Ethanol, Distilled water, Sodium hydroxide, Magnesium carbonate, Ether and Sulphuric acid, Amyl alcohol etc. 


\section{Required apparatus}

Volumetric flask, Measuring cylinder, Test tube Pipette, Beaker of different size, porcelain basin, Funnel, Filter paper, Burette, Burette stand, lamp, Tripod stand, Analytical balance, Conical flask, Water- bath, Oven, Aluminums dish, Spatula, Wire gauze, Desiccators, butyrometer, Digital Electronic balance and $\mathrm{pH}$ meter.

\section{Physico-chemical Analysis of Milk}

Milk samples for physical and chemical experiment were collected from different selected sites. The following physico-chemical parameters of the each samples were measured; $\mathrm{pH}$, moisture content, casein and fat. After collecting the sample, different test were carried out in the chemistry lab of BMC while fat was analyzed in the laboratory of DDC in Butwal Industrial Area.

\section{Determination of $\mathbf{p H}$}

$\mathrm{pH}$ is a numeric scale used to specify whether the aqueous solution is acidic or alkaline. Milk is slightly acidic close to neutral ( $\mathrm{pH} 6.6-6.7)$. The exact value depends on when the milk is produced, processing done to milk and how long it was packaged or opened. The $\mathrm{pH}$ of the milk samples were determined using digital $\mathrm{pH}$ - meter. (Hanna Instrument HI 98107, Made in Europe, Romania)

\section{Determination of moisture content}

Water content of milk is dependent upon the synthesis of lactose. Water content of milk can range from a low content in marine mammals to a high content in human milk from the dairy farm involves hauling considerable amounts of water. If water is added to cow milk the additional water is easily detectable by several methods. Moisture content is determined according to the AOAC 2000 Official Methods of Analysis. The moisture content is calculated using Equation (1):

Moisture Content percent $=\frac{\text { Weight of water }\left(\mathrm{W}_{1}\right)}{\text { Weight of milk }\left(\mathrm{W}_{0}\right)} \times 100$

Where, $\mathrm{W}_{1}=$ weight of water and $\mathrm{W}_{0}=$ weight of milk 


\section{Determination of casein}

Casein is a principle protein of milk to an extent of around 3-4 percent. It is a phosphoprotein, composed of at least 15 amino acids. Pure casein is amorphous, odourless, tasteless and hygroscopic white solid. Casein is precipitated at $\mathrm{pH}$ of around 4.5 by using acetic acid. The method of isolation of milk protein is listed below:

1. $100 \mathrm{ml}$ of milk was taken in a round bottom flask and diluted with $50 \mathrm{ml}$ water. It was heated to $45^{\circ} \mathrm{C}$. Dropwise acetic acid solution $(10 \%)$ was added slowly by stirring until precipitate was formed completely.

2. The precipitate was filtered and washed first with distilled water and then with alcohol, the precipitate was transferred to a mortar and was added some ether and grinded with pestle to remove fat. The solid material was filtered.This is crude sample of casein.

3. It was purified by following the process given in the practical book "A Core Experimental Chemistry by N.M. Khadka"'.

The process was repeated with the same quantity of different milk samples.

Casein (protein) percentage has been calculated using Equation (2).

Casein percentage $=(\mathrm{W} / \mathrm{V}) \times 100$

Where, $\mathrm{W}=$ weight of casein and $\mathrm{V}=$ volume of milk sample

\section{Determination of fat}

The fat content of milk product is an important indication of quality, both economically and physiologically. In the dairy industry, it is mainly determined by using "quick method". Spectrometric measuring methods are often used. However, these methods have to be calibrated, which is costly. Many laboratories, are using a method developed by Swiss chemist and dairy owner Niklsus Gerber, patented in 1891 under the name "Acid Butyrometer'. This method is still used because it is simple, fast, low- cost and suitable for a relatively high sample throughout. The fat content was determined by modified Gerber method as follows:

1. Clean and dry butyrometer was taken. $10 \mathrm{ml}$ sulphuric acid was transferred with the help of pipette tilting about 30 degrees.

2. $10 \mathrm{ml}$ of milk sample was measured and transferred to the butyrometer.

3. $1 \mathrm{ml}$ amyl alcohol was transferred with the help of tilt measure. 
4. The mouth of butyrometer was covered with stopper key.

5. Butyrometer was carefully shaked without inverting until the content were mixed or dissolved.

6. Butyrometer was transferred into the centrifuge machine for 3 to 5 minutes (1000-1400 rpm)

7. After centrifuge, butyrometer was kept in water-bath at $66^{\circ} \mathrm{C}$.

8. Reading was noted. Thus percentage fat was obtained.

\section{STUDY RESULTS AND DISCUSSION}

The samples of milk were analyzed by standard procedure as mentioned in chapter three using different method for each different parameter. The methods of calculation for each parameter were mentioned above and the result obtained is tabulated below;

Table 2: Physico-Chemical parameter of pouch milk samples available in Butwal

\begin{tabular}{ccccc}
\hline Parameters & DDC & Lumbini & Godhuli & Panchamrit \\
\hline $\mathrm{pH}$ & 6.70 & 6.75 & 6.69 & 6.72 \\
Moisture Content (w/w)\% & 91.1 & 90.5 & 91.45 & 90.76 \\
Casein (w/v)\% & 3.3 & 3.24 & 3.4 & 3.12 \\
Percentage Fat & 3.02 & 3.06 & 2.87 & 2.93 \\
\hline
\end{tabular}

Source: Author's calculation

\section{Variation of $\mathbf{p H}$}

$\mathrm{pH}$ is a numeric scale used to specify whether the aqueous solution is acidic or alkaline. Solutions with $\mathrm{pH}$ less than 7.0 are acidic acid and solution with $\mathrm{pH}$ greater than 7.0 are basic. Milk is slightly acidic close to neutral. The exact value depends on when the milk was produced, processing done to milk, and how long it was packaged or opened. Other compounds in milk act as buffering agents, so that mixing milk with other chemical brings their $\mathrm{pH}$ closer to neutral. Fresh milk from cow typically has $\mathrm{pH}$ between 6.5 to 6.7 .However the $\mathrm{pH}$ of milk changes over time.

All the four samples were found to be slightly acidic or close to neutral in nature having the $\mathrm{pH}$ value ranged from 6.69 to 6.75 . The $\mathrm{pH}$ value of all samples is tabulated in Table 2 and is graphically represented in Figure 1 . The $\mathrm{pH}$ range found in current study was comparable with the finding in previous investigation in a dairy pouch milk $(6.38 \pm 0.6$ to6.77 \pm 0.88$)$ (Rehman \& Salaria, 2005). 


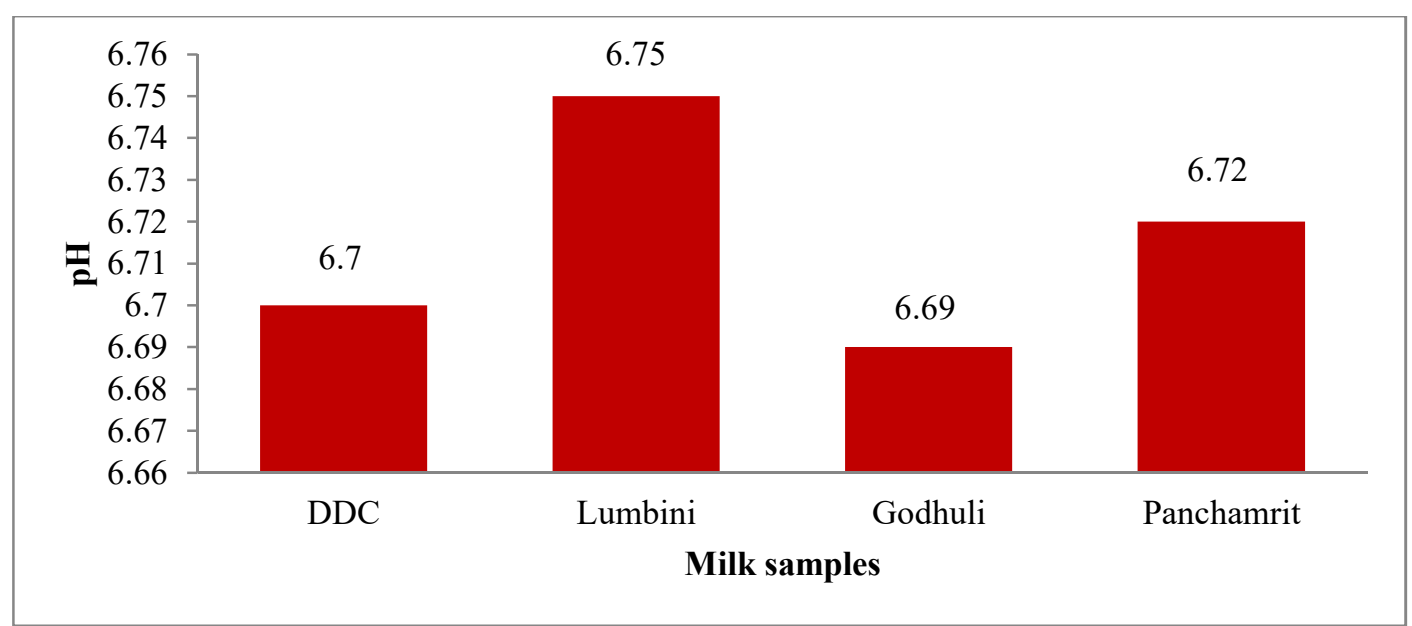

Figure 1: Variations of $\mathrm{pH}$ of different milk samples

\section{Variation of moisture content}

Moisture content or water content is the quantity of water contained in the material. In the present study the range of the moisture among for samples, Lumbini had the lowest amount moisture content (90.5) followed by Panchamrit (90.76), DDC (91.1) and Godhuli had highest (91.45). All these values were close to the earlier finding from $80 \%$ to $90 \%$ (Webb et al.,1974; Hassan et al., 2005). The results are shown in the Table 2 for further discussion and graphically represented in Figure 2.

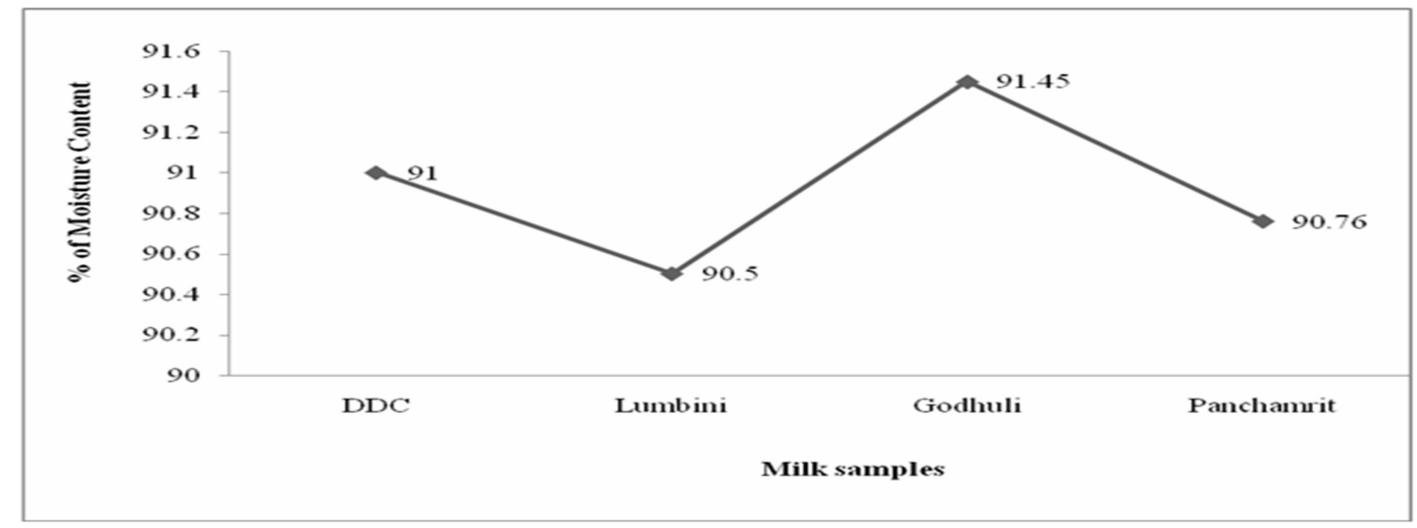

Figure 2: Variation of moisture content of different pouch milk samples 


\section{Variation of casein}

Casein is the most important protein in milk. It is over $3 / 4$ of all the amino acids contained in it. Milk contains about 3.3\% of total protein. Total milk protein and amino acid composition varies with cow breed and individual animal genetics. Quality wise milk protein is considered as one of the best for human use. Protein is the next after fat, most variant constituents of milk followed by lactose. In the present study, the percentage of milk protein (casein) varied from $3.12 \%$ (Panchamrit) to $3.4 \%$ (Godhuli), which is graphically represented by line graph in Figure 3.

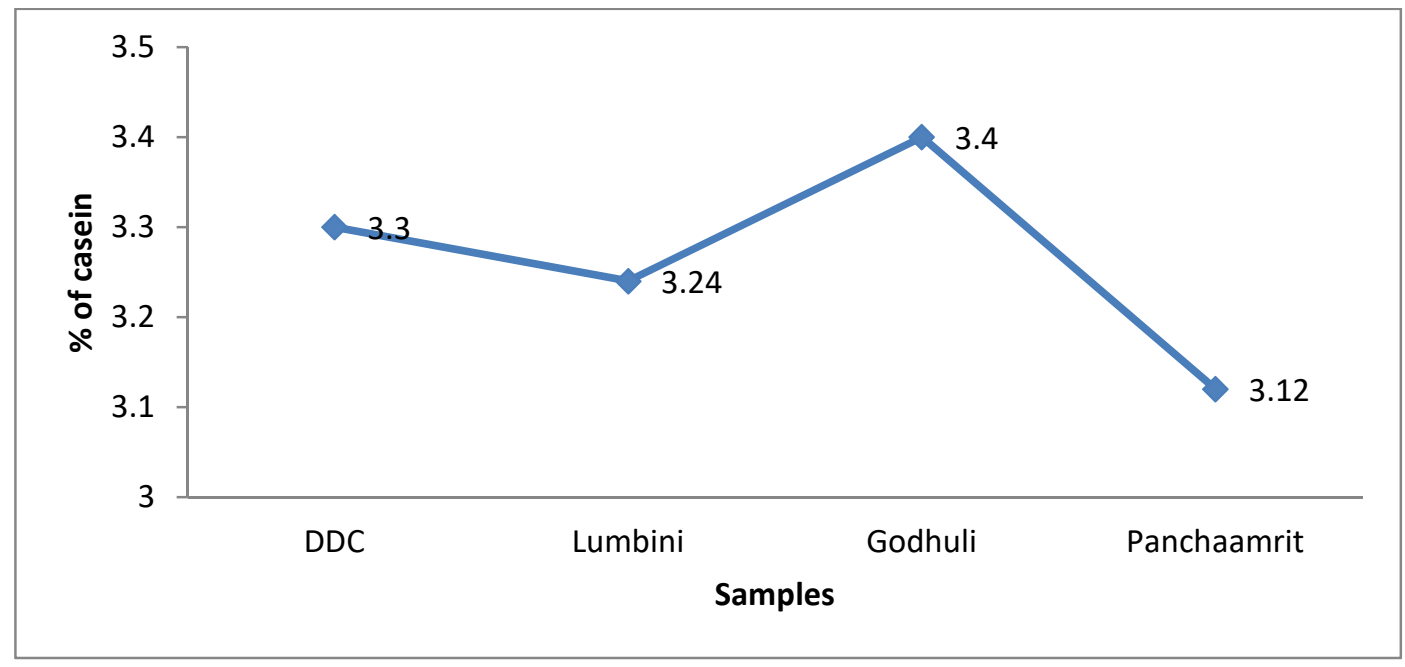

Figure 3: Variation of casein content of different milk samples

\section{Variation of fat}

The fat content, particularly of cow's milk, is modified to make a variety of products. The fat content of milk is usually stated on the container for quick recognition. The fat content of a milk product is an important indication of quality, both economically and physiologically. In the dairy industry, it is mainly determined by using "quick methods"'(Acid-Butyrometer). In the present study, percentage of the fat content was varied from $2.87 \%$ (Godhuli) to $3.06 \%$ (Lumbini), it is represented by line graph in Figure 4. 


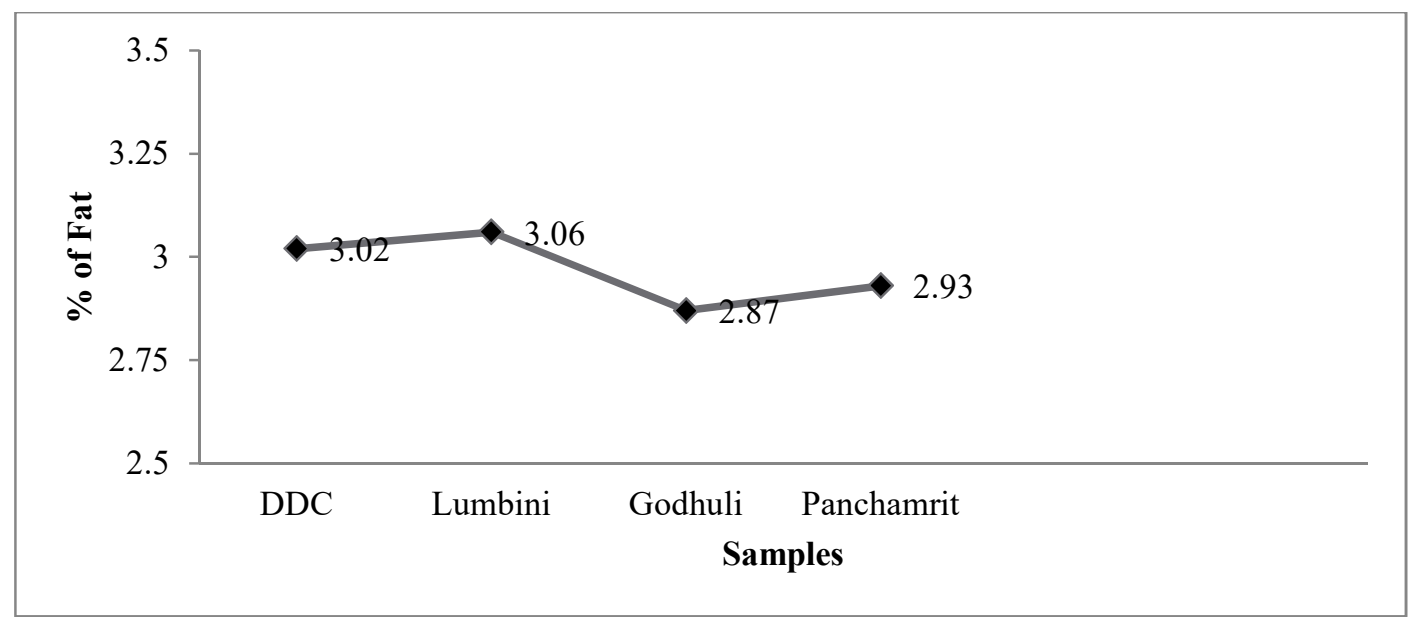

Figure 4: Variation of fat content of different milk samples

\section{CONCLUSION AND IMPLICATIONS}

In the present study, preliminary investigation were carried out to ascertain some of the physico-chemical characteristics of various pouch milk samples collected from the Butwal city. This study was designed to evaluate some physicochemical parameters and to give baseline information about the effects and health hazards caused by poor quality pouch milk. Some experimental errors, observational errors and calculation errors might occurred during experiment.

For the study DDC, Lumbini, Godhuli and Panchamrit pouch milk were taken as samples $1^{\text {st }}, 2^{\text {nd }}, 3^{\text {rd }}$ and $4^{\text {th }}$, respectively. The conclusion analyzed after research work are the $\mathrm{pH}$ value of all the milk samples was found within the limits of 6.69 to 6.75 so these samples were considered to be moderate acidic. The most acidic was Godhuli. The moisture content of the samples was found within the limits of 90.5 to 91.45 . Maximum moisture content was found in Godhuli.The percentage of casein content was found within the limits of 3.12 to 3.4. Maximum casein percentage was found in Godhuli. The percentage of fat content of the samples was found within the limits of 2.87 to 3.06. Maximum fat percentage was found in Lumbini.

In this way, the major conclusion of this study comes out to know the ideas and learn methods of detection of these parameters. The result showed that parameters of the tested 
pouch milk samples within the recommended levels. There are no any problems regarding the quality of milk and its constituent parameters. These findings may be helpful for the concerned peoples and governmental parties to monitor the quality of milk products in the market of Butwal city.

\section{REFERENCES}

AOAC (Association of Official Analytical Chemists) Official Methods of Analysis. $17^{\text {th }}$ Ed. Washington, DC: AOAC; 2000.

Ball, C, (1943). Short- Time Pasteurization of milk. Industrial \& Engineering Chemistry 35(1), pp: 71-84.

Bangladesh Standard of Dairy product, BDS-1985. Bangladesh Standard and Testing Institution, Bangladesh

Bhatia, A; Bhojak, N. and Gakkhar, N; (June 2015). Comparative Study on Physicochemical Properties of Various Milk Samples. Internationa Journal of Recent Scientific Research Vol.6, (6) pp: 4436-4439

Christison, G.W; and Ivany, K; (2006). Elimination diets in autism spectrum disorders: any wheatnamidst the chaff?. j Dev Behav Pediatr. 27(2 Suppl 2), pp: 162-171.

Gautam, S. D; Khadka. N. M; Dr. Yadav. P.N; (2013). A Core Experimental Chemistry For B.Sc; B.E and B. Tech

Hassan, SS.(2005). Quality Assurance of Various Dairy Products. Pakistan, Department of Chemistry, University of Peshawar; (M.Sc. Thesis)

Host, A. (1994). Cow,s milk protein allergy and intolerance in infancy. Some clinical, epidemiological and immunological aspects. Pediatric Allergy and Innumology. 5(5 Suppl), pp: 1-32.

Imran, M; Khan, H; Hassan ,S.S; and Khan,R; (2008). Physicochemical characteristics of various milk samples available in Pakistan. Journal of Zhejing university Sci. B 2008 July; 9(7): 546-551

Kamao, M; Tsugawa N; Suhara Y; and Okano T. (2007). Journal of Health Science, 53 (3), 25722.

Kriz and Engel, Lampman, Pavia, Sanders; (2000). Introduction to Organic Laboratory Techniques: A microscale Approach.

M Bellal Hossain, and Sima Rani Dev (Jan 2013). Comparative Study on Physiocochemical Properties of Various Milk Samples in a Selected Dairy Plant of Bangladesh. International Journal of Engineering and Applied Sciences.Vol.1, No.3,ISSN 2305-8269. 
Melnik, B.C; John, S.M; andSchmitz, G. (2013). Milk is not just food but most likely a genetic transfection system mTORCI signaling dor postnatal growth. Nutrition Journal. 12, pp: 103.

Mulloy, A; (2010). Gluten-free and casein free diets in autism spectrum disorders: A systematic review. Research in Autism Spectrum Disorders: 4(3), pp: 328-339

Ranieri, M.L; Huck, J.R; Sonnen, M; Barbano, D.M; and Boor, K.J. (2009). High temperature, short time pasteurization temperature inversely affect bacterial numbers during refrigerated storage of pasteurized fluid milk. Journal of Dairy Sciences. 92(10), pp:48234832.

Webb, Q; Dan W; Bin D; Zaijun L; and Yanqlang H.(2006). Journal of Food Composition and Analysis, 19(1), pp:76-82.

Wilson, G.S. (1943). The Pasteurization of Milk. British Medical Journal. 1(4286), pp:261-262). 